\title{
Comparative trial of six methods for the detection of CMV antibody in blood donors
}

\author{
AF HUNT, DL ALLEN, RL BROWN, BA ROBB, AY PUCKETT, CC ENTWISTLE \\ From the Regional Blood Transfusion Centre, John Radcliffe Hospital, Headington, Oxford, OX3 9DU
}

SUMMARY Six techniques were compared to find the most suitable method for determining the cytomegalovirus (CMV) antibody status of blood donors.

Five hundred and ninety-six random sera were tested by immunofluorescence (IF), complement fixation (CFT), two enzyme linked immunosorbent assays (ELISA), a commercial indirect haemagglutination test (IHA) - used as supplied, and a locally devised micromodification of the same IHA test.

Five hundred and thirty-five sera shared total agreement of results by all tests. The ELISA tests were the most discordant with other methods $(10.5 \%$ discordancies both positive and negative). IF and CFT correlated well with other tests $(0.8 \%$ discordances each $)$ but for different reasons are unsatisfactory for donor screening.

The IHA test used as supplied and its micromodification gave the most consistent results $(0.8 \%$ and $0.5 \%$ discordancies respectively). The micromodification is easy to perform and read; it compares very favourably with CFT and IF for material costs and expertise required, and readily lends itself to the testing of large numbers of sera in a reasonable time. Within certain provisos the micro-IHA technique described is recommended as the most suitable test for blood donor screening.

Cytomegalovirus (CMV) infection is a potentially lethal hazard for certain high-risk patients such an neonates, ${ }^{12}$ and individuals immunocompromised as a result of treatment or disease ${ }^{34}$ Recognition of this hazard suggests that these patients should be given blood products carrying minimal risk of transmitting this endemic virus.

Direct methods for detecting the virus are impractical for large-scale purposes. The presence of specific CMV antibody as evidence of past or present infection is therefore the most valuable indirect indicator of potentially infective blood products. Although there are many methods for detecting such antibody, the most acceptable technique for screening blood donors should be appropriate to large-scale work, reproducible, sensitive, specific, rapid (results in under four hours) and economical in order to facilitate continuity of supplies, particularly of fresh blood (for neonates) and platelets.

In consideration of the above constraints, a comparative trial was undertaken of six methods to determine the most suitable test system. Methods

Accepted for publication 23 August 1983 selected were: immunofluorescence (IF) as used routinely in this laboratory for four years, two modified enzyme-linked immunosorbent assays (ELISA) using different sources of antigen, a commercial indirect haemagglutination assay (IHA) used as supplied, a locally developed microversion of the same test, and a standard complement fixation test. This paper reports the results and conclusions from this trial on 596 random blood donor sera.

\section{Material and methods}

Five hundred and ninety-six clotted samples were obtained from random blood donors. Serum aliquots were separated within $48 \mathrm{~h}$ of collection and stored at $-30^{\circ} \mathrm{C}$ prior to assay.

Subsamples for complement fixation tests were inactivated at $56^{\circ} \mathrm{C}$ for $30 \mathrm{~min}$ immediately before assay.

ELISA

The two ELISA protocols were developed based upon published standardisation procedures ${ }^{5}$ with some minor modifications, including the substitution of LISS (low ionic strength saline) ${ }^{6}$ for PBS (phos- 
Table 1 Reaction patterns of discordant results

\begin{tabular}{|c|c|c|c|c|c|c|c|}
\hline$I F$ & $C F T$ & $E L I S A I$ & $E L I S A I I$ & $\begin{array}{l}\text { Standard } \\
\text { Cetus }\end{array}$ & $\begin{array}{l}\text { Micro } \\
\text { Cetus }\end{array}$ & $\begin{array}{l}\text { No } \\
\text { of sera } \\
(\text { Total }=61)\end{array}$ & $\begin{array}{l}\% \text { of } \\
\text { total tested }\end{array}$ \\
\hline+ & + & - & + & + & + & 18 & $3.0 \%$ \\
\hline- & - & - & + & - & - & 13 & $2 \cdot 2$ \\
\hline+ & + & + & - & + & + & 7 & $1 \cdot 2$ \\
\hline+ & + & - & - & + & + & 6 & $1 \cdot 0$ \\
\hline- & - & + & + & - & - & 3 & 0.5 \\
\hline- & + & - & + & - & - & 2 & 0.3 \\
\hline+ & - & - & + & + & + & 2 & 0.3 \\
\hline- & + & - & + & + & + & 2 & 0.3 \\
\hline+ & - & - & - & - & - & 2 & 0.3 \\
\hline- & - & - & - & + & - & 2 & 0.3 \\
\hline- & - & - & - & + & + & $2^{*}$ & 0.3 \\
\hline- & - & - & + & + & + & 1 & 0.2 \\
\hline $\mathbf{U}$ & - & + & - & - & - & 1 & $0 \cdot 2$ \\
\hline
\end{tabular}

$\mathrm{U}=$ Unreadable.

* Sera reacted with both test and control cells. Not investigated further.

phate buffered saline) as the serum diluent, which allowed reduced serum incubation times.

Commercial CMV antigens included were:

For ELISA I, a glycine buffer extracted (CF) antigen (Flow Laboratories Ltd, Irvine, Scotland)

For ELISA II a purified 'ELISA' antigen prepared by density gradient centrifugation (Tissue Culture Services Ltd, Slough, Bucks, UK)

The absorbance values $\left(E_{405}\right)$ of test and controls were determined using an MR 580 microplate reader (Dynatech Ltd)

To distinguish negative from weak positive sera by either ELISA test, five replicates of a negative control serum pool were set up on each plate.

The "cut off" was calculated from the mean of these replicates multiplied by $2 \cdot 1$.

\section{INDIRECT HAEMAGGLUTINATION ASSAY (IHA): STANDARD CETUS}

This technique was carried out using the protocol and test kits as supplied by Cetus Corporation (Berkeley, Ca 94710 USA) except that, on the recommendation of Dr J Barbara ( $\mathrm{N}$ London Transfusion Centre, personal communication) " $U$ " well plates were used and found to give improved settling patterns. Results are given under the heading "Standard Cetus."

\section{INDIRECT HAEMAGGLUTINATION ASSAY (IHA): MICRO CETUS}

In view of the relatively high cost of the standard test and the need to screen large numbers of sera, a microtest was developed as follows: For each test, $10 \mu \mathrm{l}$ of a $1 / 4$ serum dilution were dispensed into Terasaki plates with a Compupet diluter (General Diagnostics) followed by $5 \mu \mathrm{l}$ undiluted cell suspension using a Hamilton multidispenser (VA Howe Ltd)

Methods of incubation of plates and of interpreta- tion of results were as previously described.? Results are given under the heading "Micro Cetus." In both the Standard and Micro Cetus procedures the tests were left undisturbed for $2-2 \frac{1}{2} \mathrm{~h}$ or more before reading.

\section{COMPLEMENT FIXATION TESTS (CFT)}

CFTs were performed according to established methods, ${ }^{89}$ except that microtitre plates were used instead of WHO trays; since maximum sensitivity was one of our aims, an initial serum dilution of $1 / 4$ was used. The antigen preparation was a glycine extracted CF antigen (Flow Laboratories Ltd, Irvine, Scotland).

\section{IMMUNOFLUORESCENCE (IF)}

IF tests were performed according to a standard method, ${ }^{10} 11$ using substrate slides of CMV-infected (Westwood strain) fibroblasts provided by the Oxford Public Health Laboratory.

\section{Results}

All 596 sera were tested by each technique: 535 showed total agreement: 231 positive, 304 negative. Variable results were obtained with 61 sera (see Table 1). For the purpose of discussion, any result not in agreement with three or more other techniques was designated as "discordant positive" or "discordant negative". By this definition there were 83 discordant results; these are summarised in Table 2.

\section{Discussion}

Results show that apart from the ELISA technique there was good correlation between other techniques with only $19(3.0 \%)$ discordances. The poor performance of ELISA with $10.5 \%$ overall discor- 
Table 2 Summary of discordant results

\begin{tabular}{lccccc}
\hline & \multicolumn{2}{c}{ “Discordant" positive } & & \multicolumn{2}{c}{ Discordant" negative } \\
\cline { 2 - 3 } \cline { 5 - 6 } & No & $\%$ & & No & $\%$ \\
\hline IF & 2 & $0 \cdot 3$ & & 3 & $0 \cdot 5$ \\
CFT & 2 & $0 \cdot 3$ & & $0 \cdot 5$ \\
ELISA I & 4 & $0 \cdot 7$ & & 29 & $4 \cdot 9$ \\
ELISA II & 19 & $3 \cdot 2$ & & 13 & $2 \cdot 2$ \\
Standard Cetus & 5 & $0 \cdot 8$ & & 0 & 0 \\
Micro Cetus & 3 & $0 \cdot 5$ & & 0 & 0 \\
\hline
\end{tabular}

dances is at variance with other published findings. ${ }^{5}$ One possible explanation might be our use of commercial antigens rather than home produced antigens used by these workers.

However, these findings may also be explained in terms of problems encountered during the development of the ELISA tests involving the selection of the negative control serum pool and the establishment of "cut off" values. Thus there was a significant overlap of $\mathrm{E}_{405}$ values of sera shown to be CMV antibody positive or negative by other methods, and an order of magnitude variation in the range of $E_{405}$ values for sera defined as CMV antibody negative by all other methods. These problems, together with the need for considerable capital investment for plate washing and reading equipment to deal with large numbers of samples also weighed against the use of these techniques.

The immunofluorescence technique correlated well with other methods $(0.8 \%$ discordant results $)$. However, it is labour intensive, requires tissue culture facilities and considerable expertise to overcome both the biological variation in fibroblast preparations and the highly subjective interpretation of results. The method does not lend itself readily to the handling of large numbers of samples.

Standard complement fixation also correlated well with other tests $(0 \cdot 8 \%$ discordances $)$, but the need for overnight incubation to achieve necessary sensitivity made this technique unsuitable for our requirements. A shortened CFT using a two hour incubation stage at $37^{\circ} \mathrm{C}$ had been tried experimentally on 100 random sera, but because of markedly inferior sensitivity was not pursued further.

Both the Standard and Micro Cetus indirect haemagglutination assays gave excellent results $(0.8 \%$ and $0.5 \%$ discordances respectively). Both tests were easy to perform, and contrary to the experience of others, ${ }^{5}$ the interpretation of agglutination patterns did not present problems providing the tests were left to settle and read as described. Limited experiments (data not shown) suggested that CMV antibodies of both IgG and IgM immunoglobulin classes are detectable. The test kit has a stated shelf-life of six months and reconstituted cell suspensions stored at $+4^{\circ} \mathrm{C}$ are sufficiently stable to give satisfactory results for up to 14 days. The major disadvantage with the Standard Cetus IHA test as presently supplied is its high cost. However, the Micro Cetus modification described compares very favourably with other methods for material costs and for technical expertise required. Provided the sensitivity, specificity and availability of the reagents are maintained in routine production, this would be our method of choice for testing blood donor sera for determination of CMV antibody status.

\section{References}

' Benson JWT, Bodden SJ, Tobin JO'H. Cytomegalovirus and blood transfusion in neonates. Arch Dis Child 1979;54:53841.

${ }^{2}$ Yeager AS, Grumet FC, Hafleigh MT, Arvin AM, Bradley JS, Prober CG. Prevention of transfusion acquired cytomegalovirus infections in newborn infants. $J$ Pediatr 1981;98:281-7.

${ }^{3}$ Lang DJ, Ebert PA, Rodgers BM, Boggess HP, Rixse RS. Reduction of postperfusion cytomegalovirus infections following the use of leukocyte depleted blood. Transfusion 1977;17:391-5.

${ }^{4}$ Ho M. Cytomegalovirus, biology and infection. New York: Plenum Medical Books Co, 1982.

${ }^{5}$ Booth JC, Hannington B, Bakir TMF, et al. Comparison of enzyme-linked immunoabsorbent assay, radioimmunoassay, complement fixation, anticomplement immunofluorescence and passive haemagglutination techniques for detecting cytomegalovirus IgG antibody. J Clin Pathol 1982;35:13458.

- Mollison P. In: Blood transfusion in clinical medicine 7th ed. Oxford: Blackwell Scientific Publications, 1983.

' Puckett A, Pratt G. Modification of the system of screening for antisyphilis antibodies in a transfusion centre, featuring a miniaturisation of the Treponema Pallidum Haemagglutination assay. J Clin Pathol 1982;35:1349-52.

${ }^{8}$ McSwiggan DA, Taylor CED. A simplified complement fixation test for detecting syphilis antibodies. Public Health Laboratory Service Monograph series No 1. London: HMSO, 1972.

' Bradstreet P, Taylor CED. Techniques of complement fixation test applicable to diagnosis of virus disease. Mon Bull Min Hlth PHLS 1962;21:96.

${ }^{10}$ Macey JEM, Tobin JO'H. Antibodies to cytomegalovirus IgG, IgA and IgM. Immunofluorescence technique in diagnostic microbiology. Public Health Laboratory Service, Monograph No 18, London: HMSO, 1974.

" Schmitz H, Haas R. Determination of different cytomegalovirus immunoglobulins (IgG, IgA, IgM) by immunofluorescence. Archiv für die gesamte Virus Forschung 1972;37:131.

${ }^{12}$ Cameron CH, Combridge BS, Howell DR, Barbara JAJ. A sensitive immunoradiometric assay for the detection of hepatitis $B$ surface antigen. $J$ Virol Methods 1980;1:311-23.

Requests for reprints to: Dr CC Entwistle, Director, Regional Transfusion Centre, John Radcliffe Hospital, Headington, Oxford OX3 9DU, England. 